William H. Noble MD FRCP, Andrew Baker MD FRCP

\title{
MAO inhibitors and coronary artery surgery: a patient death
}

The mechanisms of action of monoamine oxidase inhibitors (MAOIs) suggest that patients taking them may respond with hyper-or hypotension when undergoing coronary artery surgery. We describe a case where MAOIs were present and fentanyl and midazolam were the anaesthetic agents used. The anaesthesia and surgery were performed without incident. Postoperative ICU care was complicated by hypertension, hyperthermia, and severe shivering followed by hypotension resistant to therapy and finally death. Diagnoses of pulmonary embolism and sepsis were unproven and may have played a role. The MAOIs may also have played a role. Reactions in patients while taking both meperidine and MAOIs are unusual and animals react differently from humans to a combination of MAOIs and narcotics. There are only five reported cases where fentanyl was given to patients on MAOIs. We conclude that, until there is more information, MAOIs should be discontinued, if possible, before surgery in which catecholamines may be needed.

Notre connaissance du mécanisme d'action des inhibiteurs de la monoamine oxydase (IMAO) porte à croire que cette médication peut provoquer une réaction hypo- ou hypertensive pendant la chirurgie des artères coronaires. Nous décrivons une observation au cours de laquelle chez un patient dejà sous IMAO, on a utilisé du fentanyl et du midazolam comme anesthésiques. Les soins postopératoires en unité de soins intensifs se sont compliqués d'hypertension, d'hyperthermie et d'un frisson violent suivis d'une hypotension rebelle à tout traitement et finalement du décès. Des diagnostics d'embolie pulmonaire et de septicémie, bien que mis en cause, n'ont pu être confirmés. L'IMAO

\section{Key words}

ATARACTIC AGENTS: MAO inhibitors; COMPLICATIONS: death; SURGERY: cardiac.

From the Department of Anaesthesia, St. Michael's Hospital and University of Toronto.

Address correspondence to: Dr. William H. Noble, Department of Anaesthesia, St. Michael's Hospital, 30 Bond St., Toronto, Ont., M5B IW8.

Accepted for publication 6th August, 1992. aurait aussi pu contribuer à cette issue fatale. Alors que les réactions chez des patients qui prennent de la mépéridine et de l'IMAO sont rares, les animaux réagissent différemmement des humains à l'association IMAO-opiacés. Seulement cinq observations de patients sous IMAO et recevant du fentanyl sont rapportées. Nous concluons qu'il est préférable de cesser les IMAO chez les patients pour lesquels on pourrait avoir recours à des.

Current recommendations ${ }^{1,2}$ concerning the anaesthetic management of patients receiving monoamine oxidase inhibitors (MAOI) suggest that there is no need to discontinue MAOIs before surgery; morphine or fentanyl may be used; meperidine should be avoided; and the classic triad of "hypoxia, hypercarbia and hypotension" be avoided.

We attempted to follow these guidelines and present a case where MAOIs were continued up to the time of coronary artery bypass grafting (CABG). We are not certain of the underlying cause of death in the ICU but suggest that MAOIs may have played a role and complicated patient management.

\section{Case report}

A 64-yr-old man with unstable angina presented for CABG. He was depressed and receiving tranylcypromine (MAOI) $30 \mathrm{mg}$ bid for ten years, chlordiazepoxide $25 \mathrm{mg}$ bid and flurazepam. He had myelodysplasia $(\mathrm{Hb} 87$ $\mathrm{g} \cdot \mathrm{dl}^{-1}$, WBC $4.910^{6} \cdot \mathrm{L}^{-1}$ ). He had had a myocardial infarction two months before surgery with continuing angina while taking digoxin, furosemide, aspirin, nitroglycerine paste, metoprolol and diltiazem. He was a smoker and while in hospital developed a left lower lobe (LLL) pneumonia requiring tracheal intubation and pulmonary ventilation for four days. Investigation revealed a normal cardiac output $(\dot{Q})$, pulmonary wedge pressure $(\mathrm{Pw})$ and matched LLL abnormalities on V/Q̈scan. He was treated with cefoxitin, salbutamol and ipratropium and one month before surgery the chest cleared on physical examination and chest radiography. He was also receiving omeprazole, iron, domperidone, and sulcralfate. On physical examination he was a large man (surface area $2 \mathrm{~m}^{2}$ ) and appeared pale but in no distress. Blood pressure was $169 / 80 \mathrm{mmHg}$ supine and $90 / 50 \mathrm{mmHg}$ standing. 
Jugular venous pressure was low and there was no peripheral oedema. The respiratory rate was 12 per min. There were no adventitious sounds.

Persantine thallium scanning demonstrated severe septal, inferior and apical ischaemia and a myocardial infarction in the inferior wall. At coronary catheterization the left main coronary artery was $80 \%$ obstructed and the right coronary artery was dominant. Therefore he was placed on an urgent list for CABG. The aspirin was stopped but all other medication was continued including tranylcypromine.

$A C A B G$ surgery was performed without difficulty. The preoperative laboratory and cardiovascular data are shown in Table I. Premedication consisted of morphine $12.5 \mathrm{mg}$, perphenazine $2.5 \mathrm{mg}$, isosorbide $15 \mathrm{mg}$, metoprolol 100 $\mathrm{mg}$, and diltiazem $60 \mathrm{mg}$. The anaesthetic was fentanyl $7 \mathrm{mg}$, midazolam $7 \mathrm{mg}$, and pancuronium $20 \mathrm{mg}$. Two coronary vessels were grafted successfully. The operative course of the patient was stable at all times including weaning from cardiopulmonary bypass. No inotropes were required in the operating room at any time

Postoperatively the patient was initially stable but management became increasingly difficult. First, there was uncommonly severe shivering and resistant hypertension. Then, labile hypotension, a high cardiac output and a fever developed.

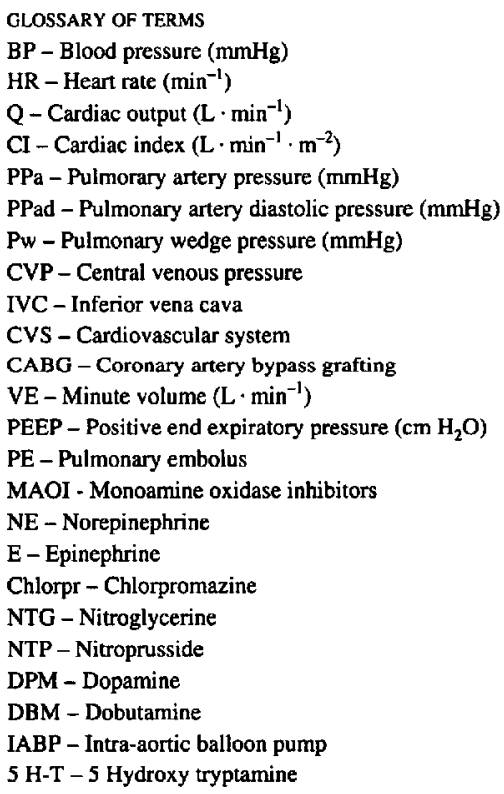

Immediate postoperative data (Table I, 13:00) indicated no problems. Fentanyl was given for sedation. The initial temperature was $35.7^{\circ} \mathrm{C}$ rectal and over hours gradually increased to $36.9^{\circ} \mathrm{C}$ associated with severe shivering. Over the same period hypertension developed. The increase in BP did not respond to nitroglycerine (NTG $80 \mathrm{mg}$ over two hours), nitroprusside (NTP - $25 \mathrm{mg}$ over one hr), nifedipine ( $20 \mathrm{mg}$ SL) or sedation (midazolam 15 $\mathrm{mg}$ and fentanyl $1 \mathrm{mg}$ ). By 20:00 (Table I) BP was 180 $\mathrm{mmHg}$ systolic. Finally chlorpromazine $(12.5 \mathrm{mg} i \mathrm{v})$ was tried. Meperidine was not used. Respiratory indices were normal.

The shivering continued despite normothermia. Hypotensive episodes developed (Table I, 21:15). The pulmonary artery diastolic to wedge pressure gradient widened and cardiac output increased. Neuromuscular blockade (vecuronium) was employed which controlled the shivering and NE was infused to increase BP. Blood gas analysis at 21:15 indicated a combined metabolic and respiratory acidosis, and hypoxaemia. Despite efforts to control these problems the patient had an asystolic cardiac arrest at 23:15 requiring four minutes of CPR. With epinephrine $1 \mathrm{mg}$ iv normal sinus rhythm and BP returned.

The patient's temperature increased to $38^{\circ} \mathrm{C}$ over the next six hours (Table II, 6:00). Blood pressure could only be maintained with norepinephrine at $1.6 \mathrm{mg} \cdot \mathrm{hr}^{-1}$. Cardiac output remained high, and PPad-Pw elevated (Table II, 6:00). Minute volume (VE) was increased (24:00) but $\mathrm{PaCO}_{2}$ increased. Progressive increases in VE were required to control the respiratory acidosis (Tables I and II, 24:00 to 6:00). The chest radiograph indicated pulmonary oedema with the right lower lobe (RLL) spared. The WBC increased as did the serum creatinine concentration. The patient was heparinized, cultures were taken and gentamycin and cefazolin were administered. As the day progressed core temperature increased to $39^{\circ} \mathrm{C}$ despite cooling and continuous neuromuscular blockade. Cardiac output decreased and BP was difficult to maintain. Besides episodes of tachycardia the ECG remained unchanged. Dopamine and epinephrine were not successful in maintaining $\dot{Q}$ and so an IABP was inserted (Table II, 22:00). The A-a $\mathrm{O}_{2}$ gradient widened, metabolic acidosis developed and urine output decreased. The patient became asystolic at 7:18 the next morning. Post mortem examination was not allowed. Two blood cultures and a urine culture were negative.

\section{Discussion}

The diagnosis of pulmonary embolus was considered in view of the high PPad-Pw gradient, the high dead space $\left(\mathrm{PaCO}_{2} 36 \mathrm{mmHg}\right.$, VE $16 \mathrm{~L} \cdot \mathrm{min}^{-1}$ with muscle relaxation to reduce the $\mathrm{CO}_{2}$ production of shivering) and the absence 
TABLE I Patient cardiorespiratory data-Day 1

\begin{tabular}{|c|c|c|c|c|c|c|}
\hline Time hr & $\begin{array}{l}\text { Preop } \\
9: 00\end{array}$ & $\begin{array}{l}\text { Postop } \\
13,00\end{array}$ & $\begin{array}{l}\text { Day } 1 \\
20: 00\end{array}$ & $\begin{array}{l}\text { Day I } \\
2 J: 15\end{array}$ & $\begin{array}{l}\text { Day I } \\
23: 10\end{array}$ & $\begin{array}{l}\text { Day } 1 \\
24: 00\end{array}$ \\
\hline $\mathrm{BP} \mathrm{mmHg}$ & $120 / 70$ & $120 / 50$ & $180 / 60$ & $80 / 40$ & $120 / 45$ & $100 / 45$ \\
\hline $\mathrm{HR} \cdot \mathrm{min}^{-1}$ & 60 & 60 & 80 & 115 & 88 & 94 \\
\hline $\mathrm{Q} \mathrm{L} \cdot \mathrm{min}^{-1}$ & 6 & 6.2 & 9.6 & 11.2 & 11.6 & 8.8 \\
\hline $\mathrm{CI} L \cdot \mathrm{m}^{-1} \cdot \mathrm{m}^{-2}$ & 3 & 3.1 & 4.8 & 5.6 & 5.8 & 4.4 \\
\hline $\mathrm{PPa} \mathrm{mmHg}$ & $46 / 18$ & $42 / 16$ & $42 / 16$ & $49 / 31$ & $62 / 30$ & $73 / 33$ \\
\hline Pw mmHg & 15 & 14 & 14 & 21 & 15 & 20 \\
\hline Temp ${ }^{\circ} \mathrm{C} \mathrm{R}$ & 36.7 & 35.7 & 36.9 & 37.2 & 37.2 & 37.0 \\
\hline $\mathrm{pH}$ & 7.48 & 7.39 & 7.38 & 7.29 & & 7.08 \\
\hline $\mathrm{PaCO}_{2} \mathrm{mmHg}$ & 39 & 38 & 36 & 46 & & 71 \\
\hline$V_{E L} \cdot \min ^{-1}$ & & 6 & 6 & 6 & & 8 \\
\hline $\mathrm{PaO}_{2} \mathrm{mmHg}$ & 431 & 360 & 103 & 72 & & 166 \\
\hline $\mathrm{FIO}_{2}$ & 1.0 & 0.9 & 0.4 & 0.4 & & 1 \\
\hline $\begin{array}{l}\text { PEEP } \mathrm{cmH}_{2} \mathrm{O} \\
\mathrm{PVOO}_{2} \mathrm{mmHg}^{2}\end{array}$ & 0 & 5 & 5 & 5 & & $\begin{array}{l}5 \\
39\end{array}$ \\
\hline $\mathrm{Hb} \mathbf{g} \cdot \mathrm{dl}^{-1}$ & 91 & 81 & 98 & & & \\
\hline WBC $10^{6} \cdot \mathrm{L}^{-1}$ & 4.5 & 11 & 6.9 & & & \\
\hline BUN mmol $\cdot \mathrm{L}^{-1}$ & 7.7 & 6.2 & & & & \\
\hline $\mathrm{Cr} \mathrm{mmol} \cdot \mathrm{L}^{-1}$ & 159 & 117 & & & & \\
\hline CVs & & & NTG & & $\mathrm{E}$ & NE \\
\hline \multirow[t]{3}{*}{ Drugs } & & & NTP & & NE & \\
\hline & & & Adalat & & & \\
\hline & & & Chlorpr & & & \\
\hline
\end{tabular}

TABLE II Patient cardiorespiratory data - Days 2 and 3

\begin{tabular}{|c|c|c|c|c|c|c|}
\hline Time $H r$ & $\begin{array}{l}\text { Day } 2 \\
1: 00\end{array}$ & $\begin{array}{l}\text { Day } 2 \\
6: 00\end{array}$ & $\begin{array}{l}\text { Day } 2 \\
10: 00\end{array}$ & $\begin{array}{l}\text { Doy } 2 \\
14: 00\end{array}$ & $\begin{array}{l}D a y 2 \\
22: 00\end{array}$ & $\begin{array}{l}\text { Day } 3 \\
2: 00\end{array}$ \\
\hline BP $\mathrm{mmHg}$ & $100 / 50$ & $110 / 60$ & $115 / 60$ & $95 / 65$ & $95 / 45$ & $85 / 60$ \\
\hline$H R \cdot m^{-1}$ & 90 & 90 & 125 & 130 & 145 & 145 \\
\hline $\mathrm{QL} \cdot \min ^{-1}$ & 9.4 & 5.2 & 4.2 & 3.1 & 7.7 & 2.4 \\
\hline CIL $\cdot \mathrm{m}^{-1} \cdot \mathrm{m}^{-2}$ & 4.7 & 2.6 & 2.1 & 1.6 & 3.9 & 1.2 \\
\hline PPa mmHg & $49 / 29$ & $46 / 31$ & $44 / 31$ & $40 / 31$ & $48 / 30$ & $50 / 38$ \\
\hline $\mathrm{Pw} \mathrm{mmHg}$ & 20 & 17 & 19 & 24 & 22 & 23 \\
\hline Temp ${ }^{\circ} \mathrm{C} \mathrm{R}$ & 36.9 & 38.3 & 37.9 & 38.5 & 37.3 & 37.6 \\
\hline pH & 7.28 & 7.31 & 7.38 & 7.26 & 7.25 & 7.30 \\
\hline $\mathrm{PaCO}_{2} \mathrm{mmHg}_{\mathrm{g}}$ & 40 & 36 & 32 & 30 & 43 & 33 \\
\hline VE L $\cdot \mathrm{min}^{-1}$ & 11.2 & 16 & 20 & 20 & 20 & 20 \\
\hline $\mathrm{PaO}_{2} \mathrm{mmHg}$ & 186 & 94 & 66 & 121 & 56 & 113 \\
\hline $\mathrm{FIO}_{2}$ & 0.8 & 0.8 & 0.8 & 0.8 & 1.0 & 1.0 \\
\hline PEEP $\mathrm{cmH}_{2} \mathrm{O}$ & 5 & 7.5 & 10 & 12.5 & 10 & 15 \\
\hline $\mathrm{PVO}_{2} \mathrm{mmHg}$ & & & 35 & & 34 & \\
\hline $\mathrm{Hb} g \cdot \mathrm{dl}^{-1}$ & & & 123 & 134 & 99 & \\
\hline $\mathrm{WBC} 10^{6} \cdot \mathrm{L}^{-1}$ & & & 22.8 & 19.3 & 20.1 & \\
\hline BUN $\mathrm{mmol} \cdot \mathrm{L}^{-1}$ & & & 8.7 & 9.9 & & \\
\hline $\mathrm{Cr} \mathrm{mmol} \cdot \mathrm{L}^{-1}$ & & & 167 & 217 & & \\
\hline CVs & $\mathrm{NE}$ & NE & NE & $\mathrm{NE}$ & NE & NE \\
\hline \multirow[t]{3}{*}{ Drugs } & DPM & & DPM & $E$ & DPM & DBM \\
\hline & & & & & $\mathrm{E}$ & $\mathbf{E}$ \\
\hline & & & & & LABP & IABP \\
\hline
\end{tabular}


of perfusion of the RLL on the chest radiograph. A pulmonary angiogram was not carried out because the patient was unstable, kidney failure was imminent and the dye dangerous; we would not have removed a pulmonary embolus (PE) even if it were diagnosed since the cardiac output was high and we would not have inserted an inferior vena cava umbrella at the first embolus. However, the high cardiac output indicated a diagnosis other than pulmonary embolus. An error in the measurement of $\dot{Q}$ was considered. The temperature measured by the thermistor on the PA catheter agreed with another independent temperature measurement. Two cardiac output machines gave the same answer. An intracardiac shunt could have resulted in a falsely high $\dot{Q}$. But there was no change in $\mathrm{PO}_{2}$ from the CVP to right ventricle to $\mathrm{PA}$ ports (therefore not a left to right shunt) and high levels of PEEP improved $\mathrm{PaO}_{2}$ (suggestive it was not a right to left cardiac shunt). Therefore $\dot{Q}$ appeared to be correct.

Sepsis was considered given the high cardiac output, shivering, fever and a high WBC in a patient with myelofibrosis. However, no source was found and cultures of blood and urine were negative. There was no response to antibiotic therapy.

A transfusion reaction may have occurred. Although the patient initially received only his own blood back from the pump, he was transfused with six units of platelets. Therefore the shivering and fever may have represented a reaction. However, no hives, bronchospasm or coagulopathy were noted.

The presence of MAOl's may have resulted in an abnormal reaction generating the entire clinical problem. It is difficult to ascertain to what extent MAOIs were involved given the variable and idiosyncratic nature of reactions in general and the patchy information available in the literature. An often reported, reaction of MAOIs in conjunction with certain narcotics is a syndrome of coma, hyperpyrexia and hypertension. ${ }^{1,2}$ We were unable to assess the patient's mental status because neuromuscular blockade was used to control shivering. Certainly hyperpyrexia and hypertension were present. Shivering is not usually a feature of this syndrome but was a prominent feature in this case. It may have appeared initially because the patient was hypothermic. Because this syndrome has been reported in conjunction with meperidine and not fentanyl we avoided meperidine and used fentanyl. Upon reviewing the literature (see below) we now question whether this conclusion was well founded.

If the patient's problems originated from something other than MAOIs, it is possible that their presence complicated another diagnosis and/or interfered with pharmacotherapy. The actions of MAOIs include many opposing mechanisms. In a recent review Wells et al. ${ }^{1}$ listed as mechanisms of actions: reduced amine synthesis, false neurotransmitters, increased cytoplasmic amines, presynaptic receptor inhibition, decreased number of presynaptic receptors and decreased number of postsynaptic receptors. The results may be either hypertension or hypotension. As well, abnormal responses to vasoactive agents may result. It would seem likely, therefore, that MAOIs at least complicated the management of our patient.

\section{Discussion of literature}

\section{Reactions of patients to meperidine while on MAOIs}

There are 12 case reports in the literature that implicate this combination. ${ }^{3-13}$ This "unusual reaction" results in hyperthermia, coma and usually hypertension but occasionally hypotension. In two cases, treatment with phenothiazines was thought to be effective. ${ }^{3,4}$ In two others, steroids were thought to be effective ${ }^{5}$ but in another case, steroids were not effective. ${ }^{10}$ Only one study reported giving meperidine to patients taking MAOIs in an attempt to elicit an adverse response. ${ }^{13}$ None of the 15 patients reacted. This suggests the "unusual reaction" is idiosyncratic and raises the issue of the frequency of the adverse event. The frequency has not been tested but the lack of response in 15 patients tested suggests it is rare.

In animals there are very different results depending on the species. In mice, morphine, pentazocine, phenazocine and meperidine all increased the $L_{50}$ by $40-50 \%$ when receiving MAOIs. ${ }^{14}$ Morphine has been given without effect to humans on MAOI who later reacted to meperidine. ${ }^{6}$ Pentazocine and phenazocine have not been associated with reactions in humans. ${ }^{15}$ In rabbits, meperidine consistently increased temperature in association with MAOIs ${ }^{16}$ but in 15 humans tested it did not. ${ }^{13}$ Therefore animal results from the combination of meperidine and MAOIs are very different from human results.

The mechanism of action that leads to the "unusual reaction" has been suggested to be an increase in the cerebral concentration of $5 \mathrm{H}-\mathrm{T} .{ }^{14}$ This results from MAOIs but is potentiated by meperidine which blocks neuronal uptake of $5 \mathrm{H}-\mathrm{T}$. The "unusual reaction" is thought to occur in only $20 \%$ of cases because the cerebral concentration of $5 \mathrm{H}-\mathrm{T}$ must reach a critical level. ${ }^{16}$ Animals treated with $5 \mathrm{H}-\mathrm{T}$ inhibitors do not increase cerebral 5 H-T and do not show the "unusual reaction." Unfortunately animals do not react in the same way as humans to the combination of meperidine and MAOIs (see above). Thus other authors suggest it is an idiosyncratic reaction ${ }^{17}$ and we conclude we do not understand the mechanism of action of the "unusual reaction."

\section{Reactions of patients to fentanyl while on MAOIs} There are five cases reported where fentanyl was given to 
a patient on MAOIs. ${ }^{18,19}$ None of these cases presented any problem. The conclusion cannot be made from these few patients that a problem does not exist. If the incidence of an idiosyncratic reaction is as rare as it appears to be with meperidine (where the advice is that we must not give meperidine to a patient taking MAOIs) we simply have insufficient data to determine if fentanyl reacts with patients receiving MAOIs.

Animal data are not helpful. One study of eight dogs found no reaction when fentanyl was given to dogs on MAOIs.* The species differences demonstrated with the meperidine data between humans, rabbits and mice bring into serious question the usefulness of the dog data.

We conclude there is simply insufficient data to help us answer the question "is fentanyl safe when patients are taking MAOIs?" Case reports describing cases with a combination of fentanyl and MAOIs should be encouraged (whether or not there is an "unusual reaction"). Certainly no one should feel comfortable with the conclusion in two recent review articles that patients on MAOIs can be given fentanyl safely. ${ }^{1,2}$ Those conclusions are based on inadequate information.

Reactions of patients to phenothiazines while on MAOIs Phenothiazines have been recommended and used to treat patients with the "unusual reaction" to meperidine while receiving MAOIs ${ }^{3,4}$ but three fatalities have been reported with the combination of phenothiazines and MAOls. ${ }^{20,21}$ One patient who died was hyperthermic and we are not told the temperature in the other two cases. The cause of these reactions is unknown and presumably rare since the combination of MAOIs and phenothiazines has been recommended in patients with psychiatric conditions.

\section{MAOIs and inotropes}

In view of the many effects of MAOIs on monoamine metabolism (e.g., epinephrine, norepinephrine, dopamine), we expect unusual results when any of these drugs are given to patients on MAOIs. But Boakes t $_{\text {al }}{ }^{22}$ found no differences in effects when NE, E, or isuprel were infused before or after MAOIs were given in four human volunteers. Phenylephrine raised BP and HR more after MAOIs than before. This is the only controlled human experiment that tests this question and the MAOI (phenelzine $15 \mathrm{mg}$ tid) was only given for seven days before the inotropes were tested. The experiment can be criticised because of the small numbers of humans tested (since we are concerned about idiosyncracies with MAOI) and because the MAOI was not given for sufficient duration. Once again

* Braverman B, ivankovich AD, McCarthy $R$. The effects of fentanyl and vasopressors on anaesthetised dogs receiving MAO inhibitors. Anesth Analg 1984; 63: 192 (Abstr). we do not have sufficient data to conclude either that MAOIs should be continued or discontinued preoperatively when a procedure is undertaken that likely will include the use of inotropes.

\section{Conclusions}

That MAOIs interfere with the normal functioning of the autonomic system. Specifically they decrease catecholamine stores, change sensitivity of postsynaptic neurons and the way endogenous or exogenous monoamines are disposed of, result in unpredictable responses to CVS drugs and idiosyncratic and extreme responses to certain drugs, and idiosyncratic and extreme autonomic responses to certain stress. This, combined with the insufficient data on the use of large doses of narcotics in conjunction with MAOIs, suggests that it is logical and prudent to discontinue MAOIs before CABG surgery whenever possible.

There is little evidence to support or refute such a claim. There is some evidence to suggest that surgery that does not involve such stress on the CVS may be safe in the presence of MAOIs. However, only two case reports suggest safety for CABG surgery.

We report a case involving $C A B G$ in a patient on MAOIs that resulted in dramatic problems managing the cardiovascular system. We hypothesize that the problems would not have occurred or would have been more easily managed in the absence of the MAOI. We report a case, review the literature and conclude that there is insufficient data to suggest that CABG surgery using high-dose fentanyl in the presence of MAOIs is safe. In view of our lack of knowledge we hope other physicians who have anaesthetized patients on MAOIs will report those experiences.

\section{References}

1 Wells DG, Bjorksten AR. Review Article: Monoamine oxidase inhibitors revisited. Can J Anaesth 1989; 36: 64-74.

2 Stack CG, Rogers $P$, Linter SPK. Monoamine oxidase inhibitors and anaesthesia; a review. Br J Anaesth 1988; 60: 222-7.

3 Mitchel RS. Fatal toxic encephalitis occurring during iproniazid therapy in pulmonary tuberculosis. Ann Intem Med 1955; 42: 417-24.

4 Papp C, Benaim $S$. Toxic effects of iproniazid in a patient with angina. BMJ 1958; 2: 1070-2.

5 Shee JC. Dangerous potentiation of pethidine by iproniazid and its treatment. BMJ 1960; 2: 507-9.

6 Taylor DC. Alaming reaction to pethidine in patients on phenelzine (Corresp). Lancet 1962; 2: 401.

7 Palmer H. Potentiation of pethidine (Corresp). BMJ 1960; 2: 944 . 
8 London DR, Milne $M D$. Danger of monoamine oxidase inhibitors (Corresp). BMJ 1962; 2: 1752.

9 Jenkins $L C$, Graves $H B$. Potential hazards of psychoactive drugs in association with anaesthesia. Can J Anaesth 1965; 2: 121-8.

10 Pells Cocks D, Passmore-Rowe A. Dangers of monoamine oxidase inhibitors (Corresp). BMJ 1962; 2: 1545-6.

11 Reid NCRW, Jones D. Pethidine and phenelzine (Corresp). BMJ 1962; 1: 408.

12 Denton PH, Borrell VM, Edwards NV. Dangers of MAO inhibitors. BMJ 1962; 2: 1752-3.

13 Evans-Prosser $C D G$. The use of pethidine and morphine in the presence of monoamine oxidase inhibitors. $B J$ Anaesth 1968: 40: 279-82.

14 Rogers $K J$, Thornton JA. The interaction between monoamine oxidase inhibitors and narcotic analgesics in mice. Br J Pharmacol 1969; 36: 470-80.

15 Cameron AG. Monoamine oxidase inhibitors and general anaesthesia (Corresp). Anaesth Intensiv Care 1986; 14: 210.

16 Penn RG, Rogers $K J$. Comparison of the effects of morphine, pethidine and pentazocine in rabbits pretreated with monoamine oxidase inhibitor. Br 3 Pharmacol 1971; 42: 485-92.

17 Duthie DJR, Nimmo WS. Adverse effects of opiod analgesic drugs. Br J Anaesth 1962; 59: 61-77.

18 El-Ganzouri AR, lvankovich AD, Braverman B, McCarthy $\boldsymbol{R}$. Monoamine oxidase inhibitors; should they be discontinued preoperatively? Anesth Analg 1985; 64: 592-6.

19 Michaels I, Serrins M, Shier NQ, Barash PG. Anesthesia for cardiac surgery in patients receiving monoamine oxidase inhibitors. Anesth Analg 1984; 63: $1041-4$.

20 Barsa JA, Saunders JC. A comparative study of tranylcypromine and pargyline. Psychopharmacologia 1964; 6: 295-8.

$21 \mathrm{MCQueen}$ EG. New Zealand committee on adverse dng reactions: fourteenth annual report. New $Z$ Med J 1980; 91: 226-9.

22 Boakes AJ, Laurence DR, Teoh PC, Barar FSK, Benedikter LT, Prichard BNC. Interactions between sympathomimetic amines and antidepressant agents in man. BMJ 1973; 1: 311-5. 